\title{
SEMA3B improves the survival of patients with esophageal squamous cell carcinoma by upregulating p53 and p21
}

\author{
HONG TANG $^{1 *}$, YUFENG WU ${ }^{1 *}$, MING LIU $^{3}$, YANRU QIN $^{2}$, HAIYING WANG ${ }^{1}$, LILI WANG $^{1}$, \\ SHAOMEI LI ${ }^{1}$, HUI ZHU ${ }^{1}$, ZHENG HE ${ }^{1}$, JUNPENG LUO ${ }^{1}$, HONGYAN WANG ${ }^{1}$, \\ QIMING WANG ${ }^{1}$ and SUXIA LUO ${ }^{1}$
}

\begin{abstract}
${ }^{1}$ Department of Internal Medicine, Affiliated Cancer Hospital of Zhengzhou University, Henan Cancer Hospital, Zhengzhou, Henan 450008; ${ }^{2}$ Department of Clinical Oncology, The First Affiliated Hospital of Zhengzhou University, Zhengzhou, Henan 450052; ${ }^{3}$ Department of Clinical Oncology, The University of Hong Kong, Hong Kong, SAR, L10-56, P.R. China
\end{abstract}

Received January 13, 2016; Accepted February 18, 2016

DOI: $10.3892 / o r .2016 .4901$

\begin{abstract}
As one of the most common malignancies, esophageal squamous cell carcinoma (ESCC) is ranked as the sixth leading cause of cancer-related death worldwide. In our previous study, by employing cDNA microarray analysis, semaphorin 3B (SEMA3B) was found to be significantly downregulated in ESCC. In the present study, SEMA3B downregulation at the mRNA level was found in 34 of 60 primary ESCCs (56.7\%) and in 6 of 9 ESCC cell lines (66.7\%) by transcription-polymerase chain reaction (RT-PCR). Moreover, immunohistochemical (IHC) staining of SEMA3B in a tissue microarray further indicated that downregulated expression of SEMA3B protein was found in 125 of 222 (56.3\%) ESCC cases and downregulation of SEMA3B protein was significantly correlated with lymph node metastasis $(\mathrm{P}=0.000)$, advanced clinicopathological stage $(\mathrm{P}=0.001)$ and poor disease-specific survival $(\mathrm{P}=0.017)$ of ESCC patients. In addition, functional studies demonstrated that the SEMA3B gene could suppress the tumorigenic ability of ESCC cells and cell motility. Furthermore, it was found that by upregulating p53 and p21 expression and inhibiting Akt (Ser473) phosphorylation, SEMA3B could induce cell cycle arrest at G1/S phase. Taken together, our results suggest that SEMA3B may be an important tumor-suppressor gene in the malignant progression of ESCC, as well as a valuable prognostic marker for ESCC patients.
\end{abstract}

Correspondence to: Dr Suxia Luo or Dr Qiming Wang, Department of Internal Medicine, Affiliated Cancer Hospital of Zhengzhou University, Henan Cancer Hospital, 127 Dong Ming Road, Zhengzhou, Henan 450008, P.R. China

E-mail: luosxrm@163.com

E-mail: qimingwang1006@163.com

*Contributed equally

Key words: esophageal squamous cell carcinoma, SEMA3B, p21, $\mathrm{p} 53$, Akt

\section{Introduction}

Characterized by high mortality and poor prognosis, esophageal cancer is one of the most common malignant tumors worldwide, and the 5-year survival rate of advanced stage esophageal squamous cell carcinoma (ESCC) patients is only 10\%. In China, ESCC is the main histologic subtype, and the Henan Province of Northern China, Linzhou and its adjacent counties have the highest incidence of ESCC worldwide $(1,2)$. Furthermore, previous studies have revealed that ESCC development is closely associated with various risk factors, such as heredity, environment and diet (3). Such as other solid tumors, the occurrence of ESCC is a long process with numerous genetic alterations, including oncogene activation and tumorsuppressor gene inactivation. As detected by comparative genome hybridization and loss of heterozygosity, $3 p$ deletion is one of the most common genetic changes in ESCC, therefore there may be one or more tumor-suppressor genes in $3 p$ (4-7). A number of genes located in $3 p$ have already been considered as candidate tumor-suppressor genes in ESCC, such as FHIT, RASSF1A, CACNA2D2, DLEC1 and PLC81 (8-11).

As a member of the semaphorin family, semaphorin $3 \mathrm{~B}$ (SEMA3B) is located in the 3p21.3 region. SEMA3B encodes a secreted protein consisting of 749 amino acids, including a signal peptide, a highly conservative Sema structure which has an immune globulin structure domain. Identified as a candidate tumor-suppressor gene, SEMA3B exhibits frequent allelic loss and downregulation in lung and breast cancer, ovarian and hepatocellular carcinoma and cholangiocarcinomas (12-15). However, the relationship between SEMA3B and ESCC occurrence and development has not been explored. In our previous study, SEMA3B was found to be frequently downregulated in ESCC specimens, which was detected by cDNA microarray analysis (16). In the present study, reverse transcription-polymerase chain reaction (RT-PCR) and immunohistochemical (IHC) staining were employed to determine SEMA3B expression at the mRNA and protein levels in clinical ESCC samples. Moreover, in vitro assays were adopted to study the tumor-suppressive function of SEMA3B. In addition, the tumor-suppressive mechanism of SEMA3B and its clinical significance in ESCC were investigated as well. 


\section{Materials and methods}

Cell lines and primary tumor specimens. Three Chinese ESCC cell lines (HKESC1, EC18 and EC109), six Japanese ESCC cell lines (KYSE30, KYSE140, KYSE180, KYSE410, KYSE510 and KYSE520; reviewed in ref. 17) and two immortalized esophageal epithelial cell lines (NE1 and NE3) were kindly provided by Professor Srivastava (Department of Pathology, University of Hong Kong). After surgical resection at Linzhou Cancer Hospital, a total of 300 primary ESCC tumor tissue samples and their paired non-tumorous tissue samples were immediately collected from the proximal resection margins. Some were quickly put into vials and stored in liquid nitrogen and other tumor tissues were routinely formalin-fixed and paraffin-embedded. Before operative treatment, no patients recruited in the study received chemotherapy or radiotherapy and the follow-up period was 60 months. Samples used in the present study were approved by the Individual Institutional Committees for Ethical Review of Research Involving Human Subjects.

Semi-quantitative reverse transcription-PCR. Through the application of TRIzol (Invitrogen, Carlsbad, CA, USA), total RNA was extracted from the cell lines and frozen ESCC tissues. Advantage RT for PCR kit (Clontech, Mountain View, CA, USA) was employed to conduct reverse transcription of total RNA $(2 \mu \mathrm{g})$ and cDNA was subjected to PCR for 30 cycles of amplification with the following pairs of primers: SEMA3B Fw, 5'-CCAGTGCCAAGAGGCGGTTC and SEMA3B Rv, 5'-AGCACCTGGGTGTGGGCTGT. The GAPDH gene served as a control with the pair of primers: GAPDH FW, 5'-CGGGAAGCTTGTCATCAATGG and GAPDH Rv, 5'-GGCAGTGATGGCATGGACTG. In order to analyze the relative grey value, the mRNA expression was quantified by Quantity One software, during which GAPDH was regarded as an internal control.

Tissue microarrays and immunohistochemistry. As previously described, tissue microarrays (TMA) containing 300 pairs of primary ESCC tissue samples and their corresponding non-tumorous tissues were constructed (19). In short, tissue sections with a thickness of $5 \mu \mathrm{m}$ were cut from tissue microarray blocks and mounted on microscope slides. By adopting the standard streptavidin-biotin-peroxidase complex method, immunohistochemistry (IHC) was performed (19). TMA slides were deparaffinized in xylene, rehydrated through a graded alcohol series and incubated with $3 \%$ hydrogen peroxide. For antigen retrieval, TMA slides were boiled in $10 \mathrm{mM}$ sodium citrate buffer $(\mathrm{pH}$ 6.0) for $15 \mathrm{~min}$ with the help of a pressure cooker. Blocked by $10 \%$ normal rabbit serum at room temperature for $30 \mathrm{~min}$, the slides were then incubated with primary anti-SEMA3B monoclonal antibody (1:50 dilution; Lifespan) at $4^{\circ} \mathrm{C}$ overnight. At a concentration of 1:75, the TMA sections were incubated with biotinylated goat anti-rabbit immunoglobulin for $30 \mathrm{~min}$ at $37^{\circ} \mathrm{C}$. Through the application of ImmPRESS ${ }^{\mathrm{TM}}$ Universal Antibody kit, primary antibody staining was visualized with NovaRed (both from Vector Laboratories, Burlingame, CA, USA) as a substrate. In the next step, the sections were counterstained with hematoxylin, dehydrated and mounted. As previously described, an immunoreactivity scoring (IRS) system was applied (19). The percentage of SEMA3B-positive cells was scored as $0,<5 \%$, negative; $1,5-25 \%$, sporadic; $2,>25-50 \%$, focal; 3,>50\%, diffuse; and the intensity of SEMA3B-positive staining was scored as 0 , negative; 1 , weak; 2 , moderate; and 3 , strong. Both the percentage of positive cells and cell staining intensity were determined in a double-blinded manner. According to the following formula, the total score was determined: Staining index $=$ intensity $\mathrm{x}$ positive rate. In the present study, a staining index of $\leq 4$ was considered to be downregulated expression and a staining index of $>4$ was considered as normal expression.

SEMA3B-30-KYSE30 (SEMA3B-30) esophageal cancer cell line construction with SEMA3B overexpression. In order to test the function and mechanism underlying growth inhibition by SEMA3B, SEMA3B was PCR amplified, sequence-verified, cloned into pcDNA3.1(+) vector (Invitrogen) and transfected into ESCC, KYSE30 cells which lacked SEMA3B expression. A stable SEMA3B-expressing clone was selected and SEMA3B cDNA was re-sequenced. Blank vector-transfected KYSE30 cells (Vec-30) were used as control. RT-PCR and western blot analysis were employed to detect SEMA3B expression. Taking GAPDH as an internal control, mRNA and protein expression was quantified by Quantity One software, to analyze the relative grey value.

Tumor-suppressive function of SEMA3B. In order to test the tumor-suppressive function of the SEMA3B gene, foci formation assay was performed. Into a 6-well plate, $1 \times 10^{3}$ SEMA3B-30 and Vec-30 cells were planted. After being cultured for 10 days, surviving colonies (>50 cells/colony) were counted with Giemsa staining and triplicate independent experiments were carried out. Moreover, cell growth rates of the SEMA3B-30 and Vec-30 cells were detected by MTT assay. At a density of $1 \times 10^{3} /$ well, the cells were seeded in a 96-well plate. According to the manufacturer's instructions, the cell growth rate was aassessed using cell proliferation MTT kit (Sigma). The experiment was conducted in triplicate.

Migration and invasion assays. For the cell migration assays, SEMA3B-30 or Vec-30 cells were cultured in a 6-well plate until confluent and the cell layer was wound using a sterile tip. After being incubated for $36 \mathrm{~h}$, the cells were photographed under a phase-contrast microscope. The experiment was conducted in triplicate. For the invasion assay, SEMA3B-30 or Vec-30 cells were starved of serum-free medium for $24 \mathrm{~h}$ before the assay. After suspension in 500- $\mu 1$ serum-free medium, the cells $\left(5 \times 10^{4}\right)$ were loaded onto the upper compartment of an invasion chamber coated with Matrigel (BD Biosciences). However, the lower compartment was filled with 500- $\mu$ 1 complete medium as chemoattractant. After $48 \mathrm{~h}$, the invasive cells were fixed, stained and counted, and independent experiments were carried out in triplicate.

Cell cycle analysis. SEMA3B-30 or Vec-30 cells $\left(1 \times 10^{6}\right)$ were cultured in RPMI-1640 medium containing 10\% fetal bovine serum (FBS). When the cells reached $70 \%$ confluency, the serum was withdrawn from the culture medium. After $72 \mathrm{~h}$, $10 \%$ FBS was added to the medium for an additional $12 \mathrm{~h}$. The 

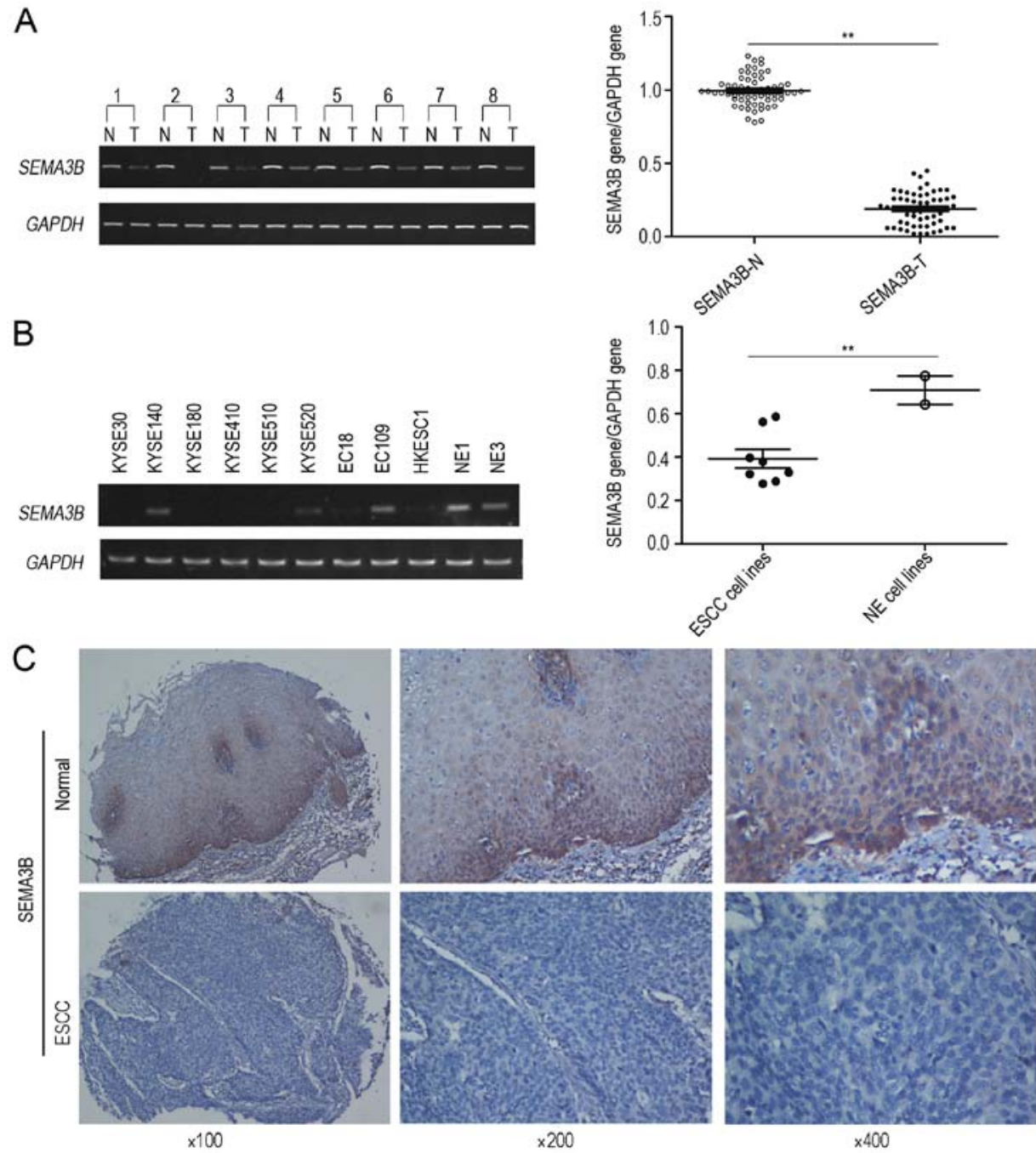

Figure 1. Downregulation of SEMA3B in ESCC. (A) The relative SEMA3B mRNA expression in tumor tissues (T) was frequently downregulated in 60 ESCCs in comparison with their paired non-tumor (N) tissues by RT-PCR. GAPDH was used as an internal control. Values are the mean \pm SD of 3 independent experiments; ${ }^{* *} \mathrm{P}<0.05$. (B) The relative SEMA3B mRNA expression in ESCC cell lines was frequently downregulated in comparison with two immortalized esophageal epithelial cell lines including NE1 and NE3 by RT-PCR. GAPDH was used as an internal control. Values are the mean \pm SD of 3 independent experiments; ${ }^{* *} \mathrm{P}<0.05$. (C) Representative images of SEMA3B expression in a pair of ESCC (lower panels) and adjacent normal tissues (upper panels) as detected by immunostaining with the anti-SEMA3B antibody (brown). The slides were counterstained with hematoxylin. Original magnification, x100 (left), x200 (middle) and x400 (right).

cells were fixed in $70 \%$ ethanol and stained with propidium iodide. In addition, DNA content was analyzed by applying Cytomics FC (Beckman Coulter).

Western blot analysis. SEMA3B-30 and Vec-30 cell lysates were obtained. Followed by protein transfer to polyvinylidene fluoride membranes (PVDF), equal amounts of protein from each sample were diluted with loading buffer, denatured and separated by $10 \%$ sodium dodecyl sulfate-polyacrylamide gel electrophoresis (SDS-PAGE). After being incubated in a blocking solution containing 5\% non-fat milk powder in Tris-buffered saline and Tween-20 (TBST) buffer $(10 \mathrm{mM}$ Tris-HCl, $\mathrm{pH} 8.0,150 \mathrm{mM} \mathrm{NaCl}$ and $0.1 \%$ Tween-20) for $1 \mathrm{~h}$ at room temperature, the membranes were immunoblotted overnight with primary monoclonal antibodies for GAPDH, p53, p21, cyclin D1, total Akt and Akt (Ser473; Cell Signaling Technology) at a dilution of $1: 1,000$ at $4^{\circ} \mathrm{C}$ and then incubated with the secondary antibody (1:1,000 dilution) for $2 \mathrm{~h}$ at room temperature. Enhanced chemiluminescence detection system was adopted to detect the protein antibody complex. The protein expression was quantified by Quantity One software, so as to analyze relative grey value, during which GAPDH served as an internal control.

Statistical analysis. SPSS standard version 16.0 was used to carry out the statistical analysis. Correlations between SEMA3B expressions and clinicopathological characteristics were assessed by $\chi^{2}$ or Fisher's exact tests. In addition, disease-specific survival (DSS) was calculated from the date of diagnosis to the date of cancer-related death or last follow-up. According to the Kaplan-Meier method, survival curves were generated and statistical analysis was performed by making use of the log-rank test. However, the Cox proportional hazards regression model was employed to identify independent prognostic factors. A P-value of $<0.05$ was considered to indicate a statistically significant result. 
Table I. Association of the downregulation of SEMA3B expression with clinicopathological characteristics of the patients with $\operatorname{ESCC}(n=222)$.

\begin{tabular}{|c|c|c|c|c|c|}
\hline \multirow{2}{*}{$\begin{array}{l}\text { Clinicopathological } \\
\text { characteristics }\end{array}$} & \multirow[b]{2}{*}{$\mathrm{n}$} & \multicolumn{2}{|c|}{ SEMA3B expression, $\mathrm{n}(\%)$} & \multirow[b]{2}{*}{$\chi^{2}$} & \multirow[b]{2}{*}{ P-value } \\
\hline & & Downregulated expression & Normal expression & & \\
\hline \multicolumn{6}{|l|}{ Age (years) } \\
\hline$\leq 60$ & 102 & $58(56.9)$ & $44(4.1)$ & 0.024 & 0.893 \\
\hline$>60$ & 120 & $67(55.8)$ & $53(44.2)$ & & \\
\hline \multicolumn{6}{|l|}{ Gender } \\
\hline Male & 126 & $70(55.6)$ & $56(44.4)$ & 0.067 & 0.891 \\
\hline Female & 96 & $55(57.3)$ & $41(42.7)$ & & \\
\hline \multicolumn{6}{|c|}{ Tumor cell differentiation } \\
\hline Well & 29 & $15(51.7)$ & $14(48.3)$ & 0.290 & 0.865 \\
\hline Moderate & 146 & $83(56.8)$ & $63(43.2)$ & & \\
\hline Poor & 47 & $27(57.4)$ & $20(42.6)$ & & \\
\hline \multicolumn{6}{|c|}{ Lymph node metastasis $(\mathrm{N})$} \\
\hline No & 125 & $55(44.0)$ & $70(56.0)$ & $1.76 \mathrm{E} 1$ & $0.000^{\mathrm{a}}$ \\
\hline N1 & 97 & $70(72.2)$ & $27(27.8)$ & & \\
\hline \multicolumn{6}{|l|}{ TNM stage } \\
\hline I & 12 & $3(25.0)$ & $9(75.0)$ & $1.49 \mathrm{E} 1$ & $0.001^{\mathrm{a}}$ \\
\hline II & 134 & $67(50.0)$ & $67(50.0)$ & & \\
\hline III & 76 & $55(72.4)$ & $21(27.6)$ & & \\
\hline \multicolumn{6}{|l|}{ General classification } \\
\hline Medullar type & 120 & $64(53.3)$ & $56(46.7)$ & 1.316 & 0.725 \\
\hline Ulcerative type & 65 & $39(60.0)$ & $26(40.0)$ & & \\
\hline Sclerotic type & 12 & $8(66.7)$ & $4(33.3)$ & & \\
\hline Mushroom type & 25 & $14(56.0)$ & $11(44.0)$ & & \\
\hline
\end{tabular}

${ }^{\mathrm{a}} \mathrm{P}<0.05$. SEMA3B, semaphorin 3B; ESCC, esophageal squamous cell carcinoma; TNM, tumor-node-metastasis.

\section{Results}

Frequent downregulation of SEMA3B in ESCCs. Our previous study showed that SEMA3B was significantly downregulated in ESCC by cDNA microarray (16), thus the expression of SEMA3B at the mRNA and protein levels was explored in the present study. The expression of SEMA3B at the mRNA level was assessed by semi-quantitative RT-PCR in 60 primary ESCC tumors as well as their paired non-tumorous tissues and 9 ESCC cell lines. The results showed that the downregulation of SEMA3B was detected in 34/60 (56.7\%) ESCC tumor tissues in comparison with their paired non-tumorous tissues. Ratios of SEMA3B gene/GAPDH expression for ESCC tissues and their paired non-tumor tissues were $0.19 \pm 0.11$ and $0.99 \pm 0.10$, respectively (Fig. 1A). In comparison with the non-tumor tissues, lower expression of SEMA3B $(\mathrm{P}<0.05)$ was found in the ESCC tissues. Meanwhile, the downregulation of the expression of SEMA3B was detected in 6/9 (66.7\%) (EC18, HYESC1, KYSE30, KYS180, KYS410 and KYS510) ESCC cell lines. Ratios of SEMA3B gene/GAPDH expression for ESCC cell lines and immortalized esophageal epithelial cell lines were $0.39 \pm 0.12$ and $0.71 \pm 0.09$, respectively $(\mathrm{P}<0.05$; Fig. 1B). Furthermore, the quantity of samples was expanded to verify its expression at the protein level. A consistent result was detected in the expression of SEMA3B at the protein level by IHC through application of TMA. Informative results were obtained from 222 pairs of ESCCs. Non-informative samples including lost samples, unrepresentative samples, samples with too few tumor cells, and samples with inappropriate staining were not involved in data analysis. Downregulation of SEMA3B at the protein level was found in 125/222 (56.3\%) informative ESCC cases (Fig. 1C).

Clinical significance of SEMA3B downregulation in ESCC. Afterwards, we examined the clinical association between the expression of SEMA3B protein and the clinicopathological characteristics of the ESCC cases. The analysis demonstrated that downregulation of SEMA3B protein was significantly correlated with lymph node metastasis $(\mathrm{P}=0.000)$ and advanced clinical stage $(\mathrm{P}=0.001$; Table $\mathrm{I})$, but was not correlated with gender, age, cell differentiation and general classification. The univariate survival analysis revealed that downregulation of SEMA3B, poor differentiation, status quo of lymph node metastasis and advanced tumor-node-metastasis (TNM) stage were significantly correlated with poor overall survival $(\mathrm{P}<0.05$; Table II). All these variables which showed statistical significance in the univariate analysis were further examined by multivariate analysis (Table III). The results revealed that 

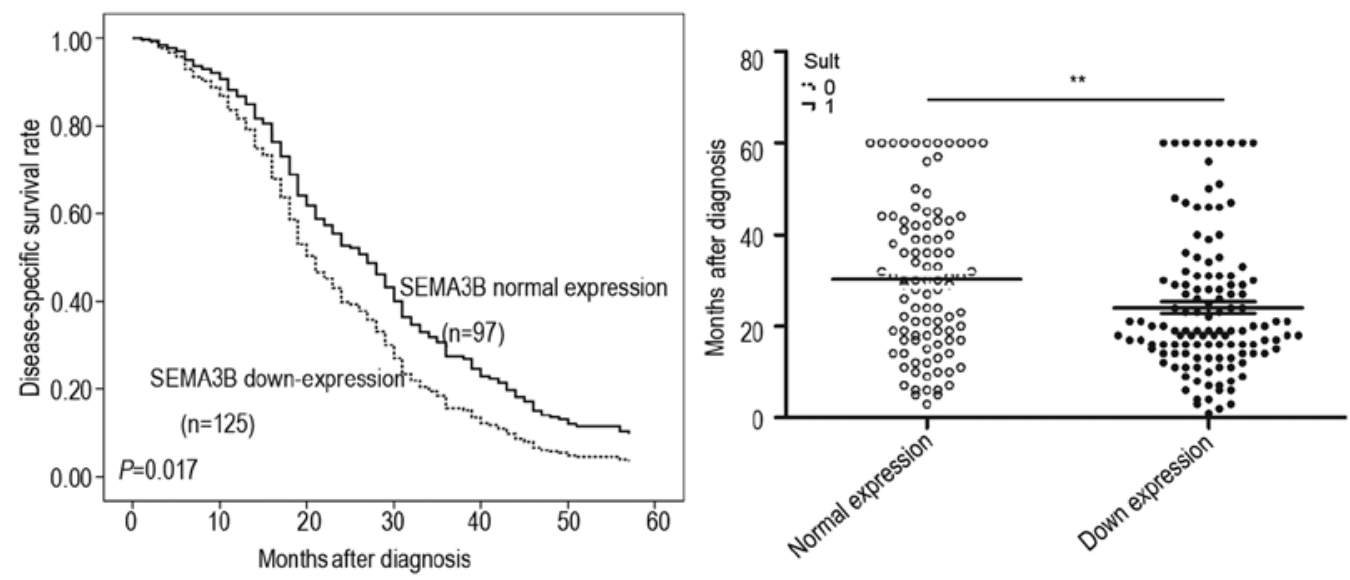

Figure 2. Kaplan-Meier analysis of survival in patients with ESCC according to SEMA3B expression. Solid line indicates patients with normal SEMA3B expression ( $\mathrm{n}=97$, median survival of 19 months); dotted line indicates patients with downregulation of SEMA3B ( $\mathrm{n}=125$, median survival of 37 months; $\mathrm{P}=0.017, \log$-rank test).

Table II. Univariate Cox regression analysis of factors possibly influencing disease-specific survival in patients with ESCC.

\begin{tabular}{lccc}
\hline Variables & Hazard ratio & $95 \%$ CI & P-value \\
\hline $\begin{array}{l}\text { SEMA3B } \\
\text { expression }\end{array}$ & 0.697 & $0.527-0.924$ & $0.012^{\mathrm{a}}$ \\
Age (years) & 1.263 & $0.958-1.667$ & 0.098 \\
Gender & 1.052 & $0.794-1.392$ & 0.725 \\
$\begin{array}{l}\text { Tumor cell } \\
\text { differentiation }\end{array}$ & 1.826 & $1.159-2.877$ & $0.009^{\mathrm{a}}$ \\
pN factor & 1.697 & $1.284-2.243$ & $0.000^{\mathrm{a}}$ \\
TNM stage & 2.093 & $1.563-2.802$ & $0.000^{\mathrm{a}}$ \\
\hline
\end{tabular}

${ }^{\mathrm{a}} \mathrm{P}<0.05$. ESCC, esophageal squamous cell carcinoma; $\mathrm{CI}$, confidence interval; SEMA3B, semaphorin 3B; TNM, tumor-node-metastasis.

Table III. Multivariate Cox regression analysis of factors possibly influencing disease-specific survival in patients with ESCC.

\begin{tabular}{lccc}
\hline Variables & Hazard ratio & $95 \%$ CI & P-value \\
\hline $\begin{array}{l}\text { SEMA3B } \\
\text { expression }\end{array}$ & 0.698 & $0.520-0.938$ & $0.017^{\mathrm{a}}$ \\
$\begin{array}{l}\text { Tumor cell } \\
\text { differentiation }\end{array}$ & 1.944 & $1.227-3.082$ & $0.005^{\mathrm{a}}$ \\
pN factor & 0.897 & $0.536-1.500$ & 0.679 \\
TNM stage & 2.143 & $1.257-3.653$ & $0.005^{\mathrm{a}}$ \\
\hline
\end{tabular}

${ }^{a} \mathrm{P}<0.05$. ESCC, esophageal squamous cell carcinoma; $\mathrm{CI}$, confidence interval; SEMA3B, semaphorin 3B; TNM, tumor-node-metastasis.

SEMA3B downregulation was an independent risk factor for overall patient survival $(\mathrm{P}=0.017)$, tumor cell differentiation $(\mathrm{P}=0.005)$ and TNM stage $(\mathrm{P}=0.005)$. The results of Kaplan-Meier analysis demonstrated that ESCC patients with
SEMA3B downregulation (median survival time, 19 months) had a shorter disease-specific survival (DSS) than patients with normal SEMA3B expression (median survival time, 30 months; P=0.017; Fig. 2).

Establishment of a stable SEMA3B-expressing cell line. The pcDNA3.1(+)-SEMA3B plasmid was constructed and its sequence was subsequently confirmed (Fig. 3A). Both the two plasmids, pcDNA3.1(+)-SEMA3B and blank vector were transfected into KYSE30 cells separately. In order to detect the transfection efficiency of the plasmids in the SEMA3B-30 cells, the SEMA3B gene and protein expression in the SEMA3B-30 cells were confirmed by RT-PCR and western blot analysis. Ratios for SEMA3B gene/GAPDH gene expression for the KYSE30, Vec-30 and SEMA3B-30 cells were $0.0068 \pm 0.0047,0.0084 \pm 0.0069$ and $0.3766 \pm 0.0574$, respectively (Fig. 3B; P<0.05). Rates for SEMA3B protein/GAPDH protein expression were $0.2321 \pm 0.0510,0.2691 \pm 0.0333$ and $0.4460 \pm 0.0343$, respectively (Fig. $3 \mathrm{C} ; \mathrm{P}<0.05$ ). In comparison with the KYSE30 and blank vector-transfected KYSE30 (Vec-30) cells, the expression of SEMA3B was higher in the SEMA3B-30 cells.

SEMA3B blocks proliferation and migration of ESCC cells. The tumor-suppressive function of SEMA3B was assessed by foci formation and cell growth assays. The mean value of the colony formation quantity of the SEMA3B-30 cells was $55.5 \pm 10.60$, which was lower than that of the Vec-30 cells $(220 \pm 46.32)$. The foci formation assay showed that the efficiency of foci formation was highly inhibited $(\mathrm{P}<0.05)$ in the SEMA3B-30 cells in comparison with the Vec-30 cells (Fig. 4A). As confirmed in the cell growth assay, the cell proliferation rate in the SEMA3B-30 cells was significantly inhibited by SEMA3B $(\mathrm{P}<0.05)$ in comparison with the Vec-30 cells (Fig. 4B) after five successive days of the measurement of $\mathrm{OD}$ values.

The TMA results indicated that the downregulation of the protein expression of SEMA3B was significantly correlated with lymph node metastasis, thus the effects by SEMA3B on cell migration and invasion were studied by wound-healing 
A
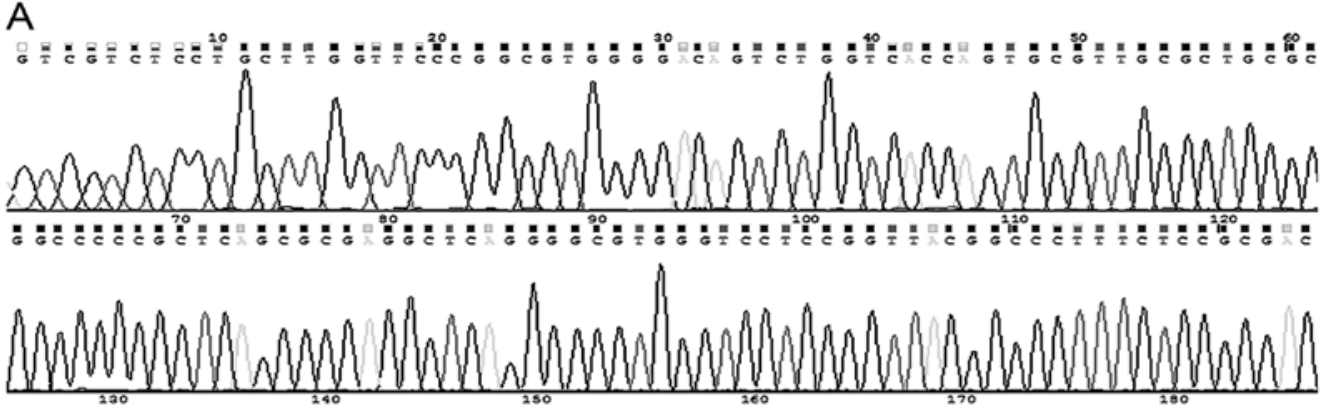

$\mathrm{B}$

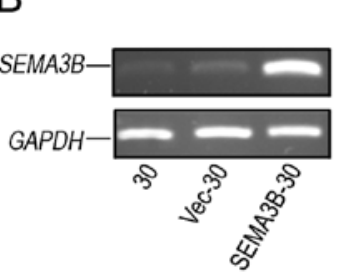

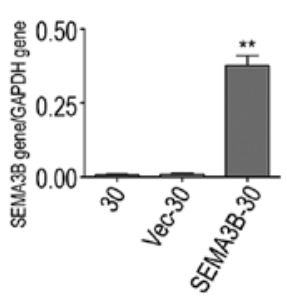

C

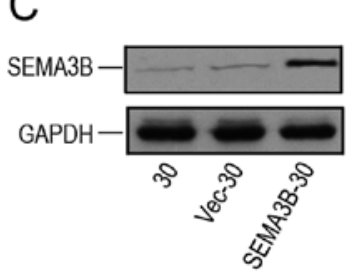

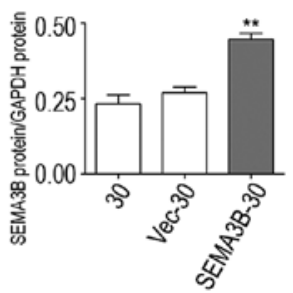

Figure 3. Establishment of a stable SEMA3B-expressing cell line. (A) The confirmatory sequence of the SEMA3B gene was re-sequenced. The relative expression of SEMA3B in the SEMA3B-transfected ESCC cells (SEMA3B-30) was confirmed by (B) RT-PCR and (C) western blot analysis. KYSE30 and empty vector-transfected ESCC (Vec-30) cells were used as controls. GAPDH was used as an internal control. Values are the mean \pm SD of 3 independent experiments; ${ }^{* *} \mathrm{P}<0.05$.
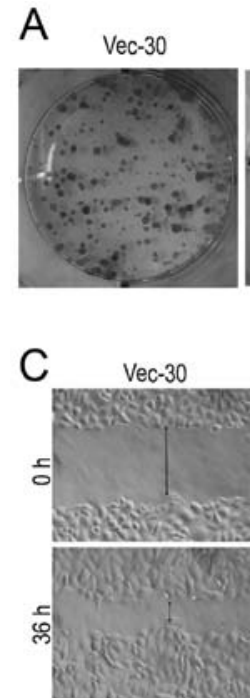

SEMA3B-30

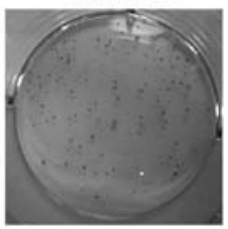

SEMA3B-30
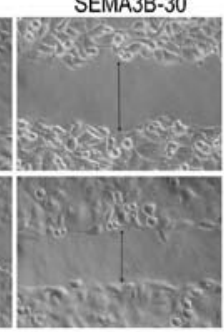
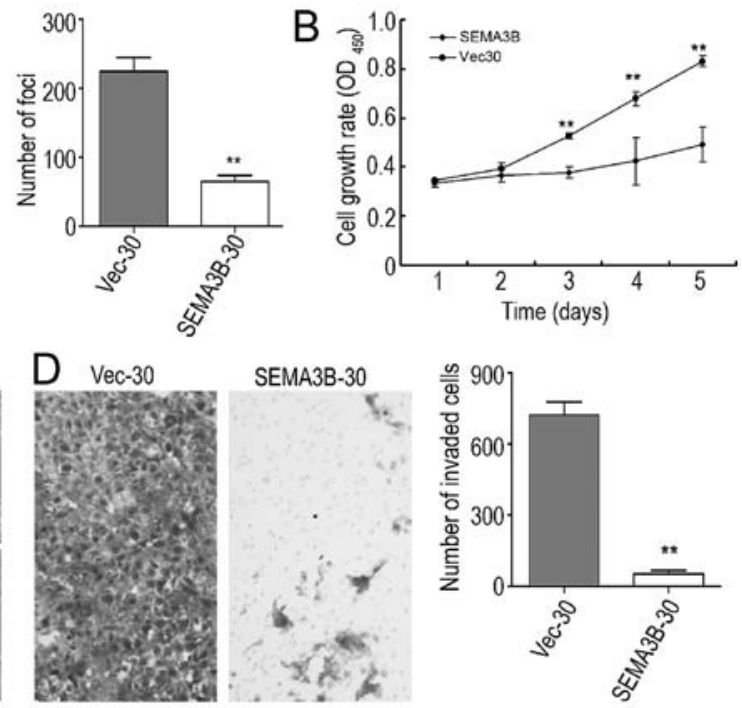

Figure 4. Tumor-suppressive function of SEMA3B in ESCC cells. (A) Representative inhibition of foci formation in monolayer culture by SEMA3B and quantitative analyses of foci quantity are shown. Columns indicate means of at least 3 independent experiments; bars, SD. ${ }^{* *} \mathrm{P}<0.05$ vs. Vec-30 cells using the Student's t-test. (B) Growth curve of SEMA3B-expressing cells was compared with Vec-30 cells by MTT assay. Data points indicate the mean of at least 3 independent experiments; bars, SD; ${ }^{* *} \mathrm{P}<0.05$. (C) Effects of SEMA3B on cell migration were determined by wound-healing assay. Within 36 h, the rate of spreading of SEMA3B-expressing cells along the wound edge was slower than that in the control Vec-30 cells. (D) The SEMA3B-30 and Vec-30 cells that invaded through the Matrigel are shown in representative images. The number of invaded tumor cells was quantified in the right histogram. Columns indicate means of triplicate experiments; ${ }^{* *} \mathrm{P}<0.05$.

and cell invasion assays. The wound-healing assay indicated that SEMA3B inhibited cell mobility (Fig. 4C). The Matrigel invasion assay also showed that the number of migrating SEMA3B-30 cells (75 \pm 30.61$)$ was lower than that of the Vec-30 cells (768.33 \pm 94.73 ; Fig. 4D). SEMA3B inhibited ESCC cell invasiveness, as the number of invasive SEMA3B-30 cells was significantly decreased in comparison with the Vec-30 cells $(\mathrm{P}<0.05)$.

SEMA3B arrests the cell cycle at the G1/S checkpoint by upregulating $p 21$ and $p 53$ and inhibits the phosphorylation of
$A k t$. To explore the mechanism underlying the growth inhibition of SEMA3B, flow cytometry was used to compare the cell cycle distribution in the SEMA3B-30 cells and the control Vec-30 cells. After 3 days of serum starvation followed by addition of $10 \%$ serum for $12 \mathrm{~h}$, significant $\mathrm{G} 1 / \mathrm{S}$ phase arrest was found in the SEMA3B-30 cells in comparison with the control Vec-30 cells. The percentage of SEMA3B-30 cells in the G1 phase was $86.35 \%$, while this percentage in the Vec-30 cells was $76.553 \%$. The percentage of SEMA3B-30 cells in the $\mathrm{S}$ phase was significantly decreased in comparison with that in the control Vec-30 cells (4.812 and 10.500\%; P<0.05; Fig. 5A). 

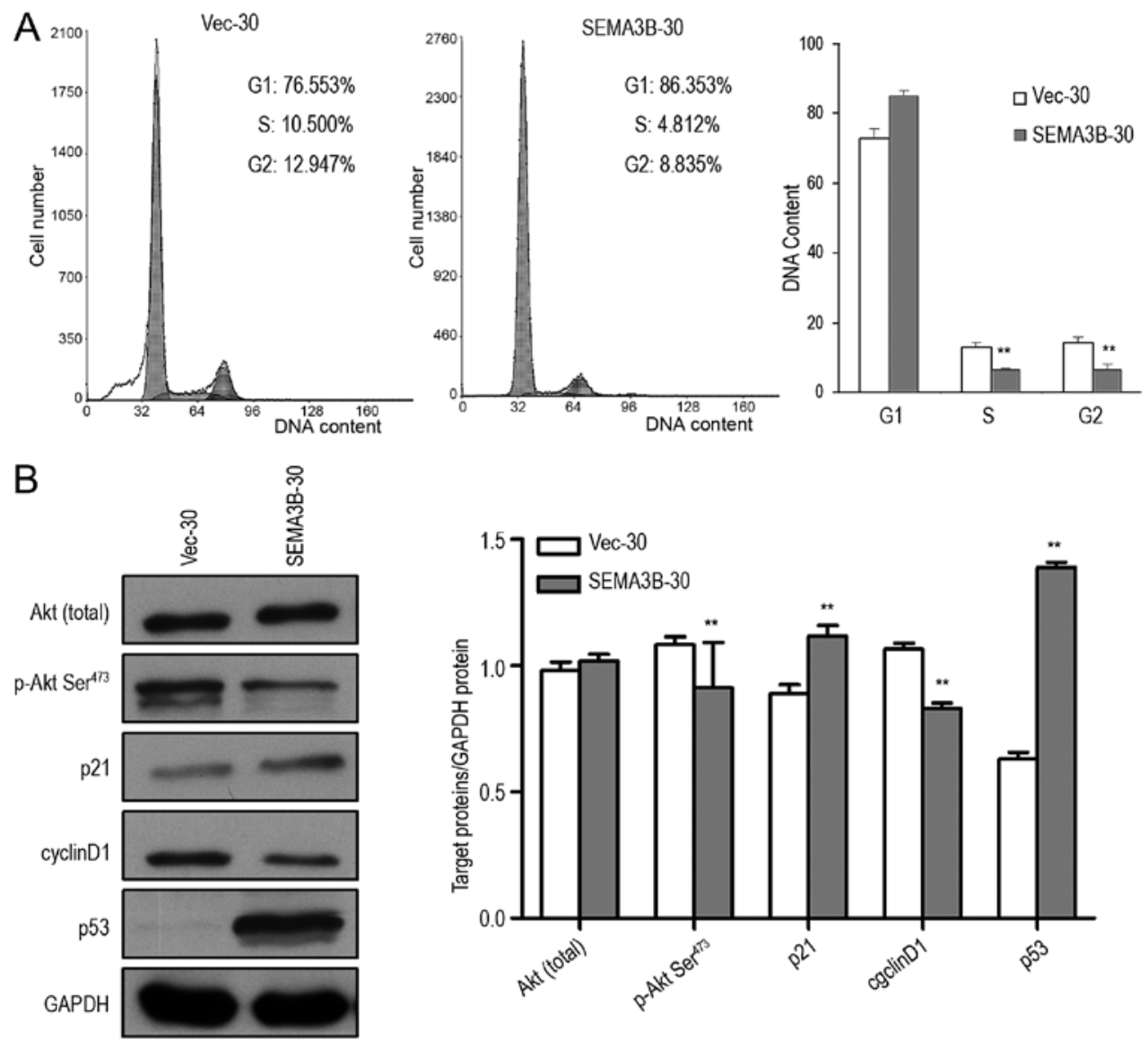

Figure 5. SEMA3B induces G1 and S cell cycle arrest. (A) Representative and summary of DNA content as detected by flow cytometry demonstrated that at the $S$ phase, the percentage of cells was much lower in the SEMA3B-expressing (SEMA3B-30) cells than that in the control Vec-30 cells. Values are the mean \pm SD of 3 independent experiments; ** $\mathrm{P}<0.05$. (B) Protein expression levels of $\mathrm{p} 21, \mathrm{p} 53$, cyclin D1, Akt (total), $\mathrm{p}$-Akt $\left(\mathrm{Ser}^{473}\right)$ were determined by employing western blot analysis. GAPDH served as an internal control. Quantification of the western blot results. p-Akt (Ser ${ }^{473}$ ), p53 and p21 expression in the SEMA3B-30 cell line was significantly higher than that noted in the Vec-30 cells, while an opposite result was found for cyclin D1. Values are the mean \pm SD of 3 independent experiments; ${ }^{* *} \mathrm{P}<0.05$.

To elucidate the potential molecular mechanism of SEMA3B in cell cycle arrest, the effects of SEMA3B were examined on several key cell cycle regulators including p21, p53, cyclin D1, and Akt from the phosphatidylinositol 3-kinase/Akt pathway. Total Akt and phosphorylated Akt (Ser473) proteins were determined by western blotting with isotype-specific antibodies. According to Fig. 5B, downregulation of phosphorylated Akt at Ser473 was significantly downregulated by SEMA3B in the SEMA3B-30 cells in comparison with that in the Vec-30 cells $(\mathrm{P}<0.05)$, while the total Akt level was not changed $(\mathrm{P}>0.05)$. Furthermore, the expression of $\mathrm{p} 21, \mathrm{p} 53$ and cyclin D1 in the SEMA3B-30 cells was found to be increased in comparison with the Vec-30 cells ( $\mathrm{P}<0.05$; Fig. 5B).

\section{Discussion}

Located at the chromosomal region 3p21.3, SEMA3B is considered as a member of the class 3 Semaphorin family, a group of secreted proteins that repulse axonal extension (20). In the present study, downregulation of SEAM3B was detected in $56.7 \%$ of 60 pairs of primary ESCC cases at the mRNA level, and $66.7 \%$ of 9 ESCC cell lines, respectively. After that, the quantity of samples was expanded, so as to verify its expression at the protein level. The tissue microarray study indicated that the absence of expression of SEMA3B at the protein level was detected in $56.3 \%$ of primary ESCCs. These consistent observations indicated the downregulation of SEMA3B in ESCC. Furthermore, the relationship between gene and clinical pathological characteristics indicated that the downregulation of SEMA3B was more frequently observed in patients with lymph node metastasis $(\mathrm{P}=0.000)$, advanced clinical stage $(\mathrm{P}=0.001)$ and poor survival $(\mathrm{P}=0.017)$. The Kaplan-Meier analysis showed that the overall survival rate of ESCC patients decreased as SEMA3B was downregulated in the tumor tissues. The multivariate analysis indicated that downregulation of SEMA3B could be used as an independent prognostic predictor for ESCC patients. Chromosome 3 allelic loss and promoter hypermethylation may be the main cause of SEMA3B downregulation (21-26).

It is well known that SEMA3B has marked ability to induce tumor cell apoptosis and regulate cell growth in lung and breast cancer, and other solid tumors $(13,14,21,27,28)$. In order to explore the function and mechanism of antitumorigenic properties of SEMA3B in ESCC cells, a stable SEMA3Bexpressing ESCC cell line, SEMA3B-30, was established. The tumor-suppressive function of SEMA3B was investigated in our in vitro assay. The result indicated that SEMA3B could significantly suppress cell growth, decrease foci formation 
and inhibit ESCC cell migration and invasion. Further study revealed that SEMA3B could inhibit the phosphorylation of Akt expression, indicating that the tumor-suppressive function of SEMA3B in ESCC may be correlated with the PI3K/AKT signaling transduction pathway. Known as protein kinase B, Akt is activated downstream of PI3K in response to receptor stimulation and modulates the function of numerous substrates involved in the regulation of cell survival, cell cycle progression and cell growth (29-34). Phospho-Akt leads to activation of MDM-2, which targets p53 for degradation (35-38), whereas inactivation of apoptotic regulators and apoptotic factors may conversely take place. Akt activation promotes cell cycle progression and cell growth by impeding nuclear localization of p21 and p27 which are cyclin-dependent kinase inhibitors; inhibiting glycogen synthase kinase-3 (GSK-3) so as to lead to the stabilization of expression of cyclin D1; maintaining levels of the anti-apoptotic protein survivin (39-42). Our results revealed that SEMA3B was able to arrest ESCC cells at the G1/S checkpoint through inhibition of the phosphatidylinositol 3-kinase/AKT signaling transduction pathway, upregulation of p53 and p21 expression and downregulation of cyclin D1 expression.

Moreover, it has been confirmed that SEMA3B induced IL-8 secretion from tumor cell by initiating the $\mathrm{p} 38$-mitogen-activated protein kinase pathway. The release of IL-8 induced the recruitment of tumor-associated macrophages which may promote cancer progression and metastasis $(43,44)$. Recent studies indicate that SEMA3B reduces invasive properties by inhibiting MMP-2, MMP-9, $\alpha v \beta 3$ and pro-angiogenesis genes and by upregulating anti-angiogenesis genes in endometrial cancer cells (45). Previous studies indicated that TIMP3, which is an inhibitor of MMP and also a key player in tumor cell invasion, angiogenesis and cell growth processes, was found to be upregulated under SEMA restoration (46). In contrast, SEMA3B shares similar binding sites on NP-1 and NP-2 proteins with VEFG165, acting as an autocrine survival factor $(28,47)$. SEMA3B competes with VEFG165 for binding on the tumor cell surface. Therefore, SEMA3B mediates its tumor-suppressing effects, at least in part, by blocking VEGF autocrine activity.

In summary, for the first time, the results of the present study demonstrated that downregulation of SEMA3B was frequently found in ESCC tumor specimens and predicted a worse prognosis of ESCC patients. Our results indicate that SEMA3B may be an important tumor-suppressor gene in the malignant progression of ESCC and a valuable prognostic marker for ESCC patients. Further research needs to be conducted in in vivo studies and the reasons for SEMA3B downregulation require further investigation.

\section{References}

1. Ke L: Mortality and incidence trends from esophagus cancer in selected geographic areas of China circa 1970-90. Int J Cancer 102: 271-274, 2002.

2. Parkin DM, Bray FI and Devesa SS: Cancer burden in the year 2000. The global picture. Eur J Cancer 37 (Suppl 8): S4-66, 2001.

3. Jemal A1, Bray F, Center MM, Ferlay J, Ward E, Forman D: Global cancer statistics. CA Cancer J Clin 61: 69-90, 2011.

4. Yen CC, Chen YJ, Chen JT, Hsia JY, Chen PM, Liu JH, Fan FS, Chiou TJ, Wang WS and Lin CH: Comparative genomic hybridization of esophageal squamous cell carcinoma: Correlations between chromosomal aberrations and disease progression/ prognosis. Cancer 92: 2769-2777, 2001.
5. Kwong D, Lam A, Guan X, Law S, Tai A, Wong J and Sham J: Chromosomal aberrations in esophageal squamous cell carcinoma among Chinese: Gain of $12 p$ predicts poor prognosis after surgery. Hum Pathol 35: 309-316, 2004.

6. Qin YR, Wang LD, Kwong D, Gao SS, Guan XY, Zhuang ZH, Fan ZM, Deng W and Hu L: Comparative genomic hybridization: The profile of chromosomal imbalances in esophageal squamous cell carcinoma. Zhonghua Bing Li Xue Za Zhi 34: 80-83, 2005 (In Chinese).

7. Ogasawara S, Maesawa C, Tamura G and Satodate R: Frequent microsatellite alterations on chromosome $3 p$ in esophageal squamous cell carcinoma. Cancer Res 55: 891-894, 1995.

8. Dammann R, Li C, Yoon JH, Chin PL, Bates S and Pfeifer GP: Epigenetic inactivation of a RAS association domain family protein from the lung tumour suppressor locus 3p21.3. Nat Genet 25: 315-319, 2000.

9. Ji L, Nishizaki M, Gao B, Burbee D, Kondo M, Kamibayashi C, Xu K, Yen N, Atkinson EN, Fang B, et al: Expression of several genes in the human chromosome 3 p21.3 homozygous deletion region by an adenovirus vector results in tumor suppressor activities in vitro and in vivo. Cancer Res 62: 2715-2720, 2002.

10.Daigo Y, Nishiwaki T, Kawasoe T, Tamari M, Tsuchiya E and Nakamura Y: Molecular cloning of a candidate tumor suppressor gene, DLC1, from chromosome 3p21.3. Cancer Res 59: 1966-1972, 1999.

11. Fu L, Qin YR, Xie D, Hu L, Kwong DL, Srivastava G, Tsao SW and Guan XY: Characterization of a novel tumor-suppressor gene PLC delta 1 at 3 p22 in esophageal squamous cell carcinoma. Cancer Res 67: 10720-10726, 2007.

12. Castro-Rivera E, Ran S, Thorpe P and Minna JD: Semaphorin 3B (SEMA3B) induces apoptosis in lung and breast cancer, whereas VEGF $_{165}$ antagonizes this effect. Proc Natl Acad Sci USA 101: 11432-11437, 2004.

13. Tomizawa Y, Sekido Y, Kondo M, Gao B, Yokota J, Roche J, Drabkin H, Lerman MI, Gazdar AF and Minna JD: Inhibition of lung cancer cell growth and induction of apoptosis after reexpression of $3 \mathrm{p} 21.3$ candidate tumor suppressor gene $S E M A 3 B$. Proc Natl Acad Sci USA 98: 13954-13959, 2001.

14. Tse C, Xiang RH,Bracht T and Naylor SL: Human Semaphorin $3 B$ (SEMA3B) located at chromosome 3p21.3 suppresses tumor formation in an adenocarcinoma cell line. Cancer Res 62: 542-546, 2002.

15. Tischoff I, Markwarth A, Witzigmann H, Uhlmann D, Hauss J, Mirmohammadsadegh A, Wittekind C, Hengge UR and Tannapfel A: Allele loss and epigenetic inactivation of 3p21.3 in malignant liver tumors. Int J Cancer 115: 684-689, 2005.

16. Qin YR1, Tang H, Xie F, Liu H, Zhu Y, Ai J, Chen L, Li Y, Kwong DL, Fu L, Guan XY: Characterization of tumorsuppressive function of SOX6 in human esophageal squamous cell carcinoma. Clin Cancer Res 17: 46-55, 2011.

17. Shimada Y, Imamura M, Wagata T, Yamaguchi $N$ and Tobe T: Characterization of 21 newly established esophageal cancer cell lines. Cancer 69: 277-284, 1992.

18. Xie D, Sham JS, Zeng WF, Lin HL, Che LH, Wu HX, Wen JM, Fang Y, Hu L and Guan XY: Heterogeneous expression and association of beta-catenin, p16 and c-myc in multistage colorectal tumorigenesis and progression detected by tissue microarray. Int J Cancer 107: 896-902, 2003.

19. Brown RS and Wahl RL: Overexpression of Glut-1 glucose transporter in human breast cancer. An immunohistochemical study. Cancer 72: 2979-2985, 1993.

20. Zou Y, Stoeckli E, Chen H and Tessier-Lavigne M: Squeezing axons out of the gray matter: A role for slit and semaphorin proteins from midline and ventral spinal cord. Cell 102: 363-375, 2000.

21. Loginov VI, Dmitriev AA, Senchenko VN, Pronina IV, Khodyrev DS, Kudryavtseva AV, Krasnov GS, Gerashchenko GV, Chashchina LI, Kazubskaya TP, et al: Tumor suppressor function of the SEMA3B gene in human lung and renal cancers. PLoS One 10: e0123369, 2015.

22. Senchenko VN,Liu J,Loginov W, Bazov I, Angeloni D, Seryogin Y, Ermilova V, Kazubskaya T, Garkavtseva R, Zabarovska VI, et al: Discovery of frequent homozygous deletions in chromosome 3p21.3 LUCA and AP20 regions in renal, lung and breast carcinomas. Oncogene 23: 5719-5728, 2004.

23. Ito M, Ito G, Kondo M, Uchiyama M, Fukui T, Mori S, Yoshioka H, Ueda Y, Shimokata K and Sekido Y: Frequent inactivation of RASSF1A, BLU, and SEMA3B on $3 \mathrm{p} 21.3$ by promoter hypermethylation and allele loss in non-small cell lung cancer. Cancer Lett 225: 131-139, 2005. 
24. Loginov VI, Khodyrev DS, Pronina IV, Maliukova AV Kazubskaia TP, Ermilova VD, Gar'kavtseva RF, Zabarovskiu ER and Braga EA: Two CpG-islands of SEMA3B gene: Methylation in clear cell renal cell carcinoma. Mol Biol 43: 1088-1092, 2009 (In Russian).

25. Chen R, Zhuge X, Huang Z, Lu D, Ye X, Chen C, Yu J and Lu G: Analysis of SEMA3B methylation and expression patterns in gastric cancer tissue and cell lines. Oncol Rep 31: 1211-1218, 2014

26. Wang K, Ling T, Wu H and Zhang J: Screening of candidate tumor-suppressor genes in 3 p21.3 and investigation of the methylation of gene promoters in oral squamous cell carcinoma Oncol Rep 29: 1175-1182, 2013.

27. Kuroki T, Trapasso F, Yendamuri S, Matsuyama A, Alder H, Williams NN, Kaiser LR and Croce CM: Allelic loss on chromosome $3 \mathrm{p} 21.3$ and promoter hypermethylation of semaphorin 3B in non-small cell lung cancer. Cancer Res 63: 3352-3355, 2003.

28. Castro-Rivera E, Ran S, Brekken RA and Minna JD: Semaphorin 3B inhibits the phosphatidylinositol 3-kinase/Akt pathway through neuropilin-1 in lung and breast cancer cells. Cancer Res 68: 8295-8303, 2008.

29. Dudek H, Datta SR, Franke TF, Birnbaum MJ, Yao R, Cooper GM, Segal RA, Kaplan DR and Greenberg ME: Regulation of neuronal survival by the serine-threonine protein kinase Akt. Science 275: 661-665, 1997.

30. Kennedy SG, Wagner AJ, Conzen SD, Jordán J, Bellacosa A, Tsichlis PN and Hay N: The PI 3-kinase/Akt signaling pathway delivers an anti-apoptotic signal. Genes Dev 11: 701-713, 1997.

31. Manning BD and Cantley LC: AKT/PKB signaling: Navigating downstream. Cell 129: 1261-1274, 2007.

32. Carnero A, Blanco-Aparicio C, Renner O, Link W and Leal JF: The PTEN/PI3K/AKT signalling pathway in cancer, therapeutic implications. Curr Cancer Drug Targets 8: 187-198, 2008

33. Janku F, Stewart DJ and Kurzrock R: Targeted therapy in non-small-cell lung cancer - is it becoming a reality? Nat Rev Clin Oncol 7: 401-414, 2010.

34. Reungwetwattana T, Weroha SJ and Molina JR: Oncogenic pathways, molecularly targeted therapies, and highlighted clinical trials in non-small-cell lung cancer (NSCLC). Clin Lung Cancer 13: 252-266, 2012.

35. Datta SR, Dudek H, Tao X, Masters S, Fu H, Gotoh Y and Greenberg ME: Akt phosphorylation of BAD couples survival signals to the cell-intrinsic death machinery. Cell 91: 231-241, 1997.

36. Brunet A, Bonni A, Zigmond MJ, Lin MZ, Juo P, Hu LS, Anderson MJ, Arden KC, Blenis J and Greenberg ME: Akt promotes cell survival by phosphorylating and inhibiting a Forkhead transcription factor. Cell 96: 857-868, 1999.
37. Cardone MH, Roy N, Stennicke HR, Salvesen GS, Franke TF, Stanbridge E, Frisch S and Reed JC: Regulation of cell death protease caspase-9 by phosphorylation. Science 282: 1318-1321, 1998.

38. Sherr CJ and Weber JD: The ARF/p53 pathway. Curr Opin Genet Dev 10: 94-99, 2000

39. Shin I, Yakes FM, Rojo F, Shin NY, Bakin AV, Baselga J and Arteaga CL: PKB/Akt mediates cell-cycle progression by phosphorylation of $\mathrm{p} 27^{\mathrm{Kipl}}$ at threonine 157 and modulation of its cellular localization. Nat Med 8: 1145-1152, 2002.

40. Diehl JA, Cheng M, Roussel MF and Sherr CJ: Glycogen synthase kinase-3beta regulates cyclin D1 proteolysis and subcellular localization. Genes Dev 12: 3499-3511, 1998.

41. Zhou BP, Liao Y, Xia W, Spohn B, Lee MH and Hung MC: Cytoplasmic localization of p21Cip1/WAF1 by Akt-induced phosphorylation in HER-2/neu-overexpressing cells. Nat Cell Biol 3: 245-252, 2001.

42. Oliveira CS, de Bock CE, Molloy TJ, Sadeqzadeh E, Geng XY, Hersey P, Zhang XD and Thorne RF: Macrophage migration inhibitory factor engages $\mathrm{PI} 3 \mathrm{~K} / \mathrm{Akt}$ signalling and is a prognostic factor in metastatic melanoma. BMC Cancer 14: 630, 2014.

43. Rolny C, Capparuccia L, Casazza A, Mazzone M, Vallario A Cignetti A, Medico E, Carmeliet P, Comoglio PM and Tamagnone L: The tumor suppressor semaphorin 3B triggers a prometastatic program mediated by interleukin 8 and the tumor microenvironment. J Exp Med 205: 1155-1171, 2008.

44. Wyckoff JB, Wang Y, Lin EY, Li JF, Goswami S, Stanley ER, Segall JE, Pollard JW and Condeelis J: Direct visualization of macrophage-assisted tumor cell intravasation in mammary tumors. Cancer Res 67: 2649-2656, 2007.

45. Nguyen H, Ivanova VS, Kavandi L, Rodriguez GC, Maxwell GL and Syed V: Progesterone and 1,25-dihydroxyvitamin $\mathrm{D}_{3}$ inhibit endometrial cancer cell growth by upregulating semaphorin 3B and semaphorin 3F. Molecular cancer research. Mol Cancer Res 9: 1479-1492, 2011.

46. Tunuguntla R, Ripley D, Sang QX and Chegini N: Expression of matrix metalloproteinase-26 and tissue inhibitors of metalloproteinases TIMP-3 and -4 in benign endometrium and endometrial cancer. Gynecol Oncol 89: 453-459, 2003.

47. Staton CA, Shaw LA, Valluru M, Hoh L, Koay I, Cross SS, Reed MW and Brown NJ: Expression of class 3 semaphorins and their receptors in human breast neoplasia. Histopathology 59: 274-282, 2011. 